\title{
Orthostatic arterial hypotension
}

\author{
Hipotensiunea arterială ortostatică

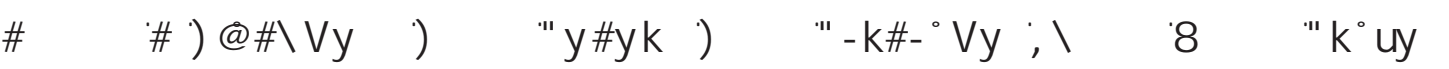

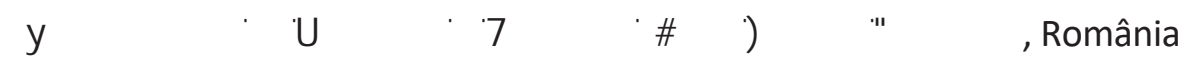

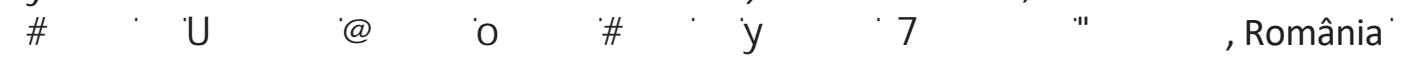

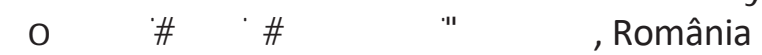

\begin{abstract}
Orthostatic hypotension is a persistent decrease of systolic blood pressure by at least $20 \mathrm{~mm} \mathrm{Hg}$ and/or diastolic blood pressure by at least $10 \mathrm{~mm} \mathrm{Hg}$ in the first 3 minutes upon standing. Orthostatic hypotension is more common in the elderly patients, being one of relatively frequent causes of hospitalization in the elderly population. Orthostatic hypotension may be primary or secondary, acute or chronic. Its etiology is represented in most cases by the primary or secondary autonomic failure. Clinical manifestations of orthostatic hypotension occur after the transition from supine to standing, and are due to cerebral hypoperfusion. These consist of nausea, dizziness, generalized weakness, postural instability, fatigue, blurred vision. Cardiological and neurological consult are necessary for diagnosis. Pharmacological treatment of orthostatic hypotension is often unsatisfactory, imposing combination with non-pharmacological measures.
\end{abstract}

Keywords: orthostatic hypotension, autonomic dysfunction

\begin{abstract}
REZUMAT
Hipotensiunea ortostatică reprezintă scăderea tensiunii arteriale sistolice cu cel puțin $20 \mathrm{~mm} \mathrm{Hg}$ și/sau a tensiunii diastolice cu cel puțin $10 \mathrm{~mm} \mathrm{Hg}$ în primele 3 minute după asumarea poziției ortostatice. Hipotensiunea or tostatică este mai frecvent întâlnită la pacienții vârstnici, fiind una dintre cauzele relativ frecvente de internare la vârstnici. Hipotensiunea ortostatică poate fi primară sau secundară, acută sau cronică. Etiologia sa este reprezentată în majoritatea cazurilor de insuficiență autonomă primară sau secundară. Manifestările clinice de hipotensiune ortostatică apar la trecerea din clinostatism în ortostatism, fiind datorate hipoperfuziei cerebrale. Acestea constau în amețeală, vertij, senzație de slăbiciune generalizată, instabilitate posturală, fatigabilitate, vedere încețoșată. Pentru diagnostic este necesar consult cardiologic și neurologic. Tratamentul medicamentos al hipotensiunii ortostatice este de cele mai multe ori nesatisfăcător, impunându-se asocierea cu mijloace nefarmacologice.
\end{abstract}

Cuvinte cheie: hipotensiune ortostatică, insuficiență autonomă

\section{INTRODUCERE}

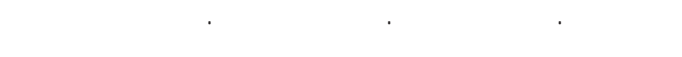

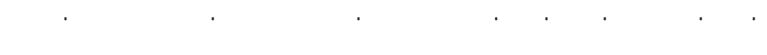

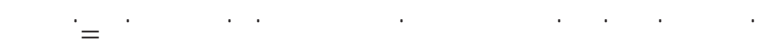

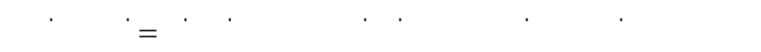

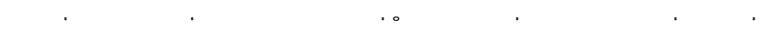

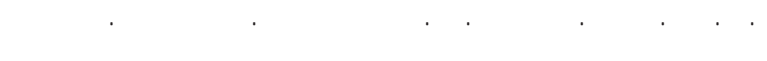

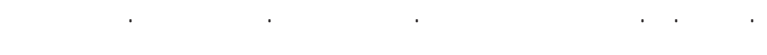

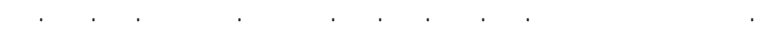

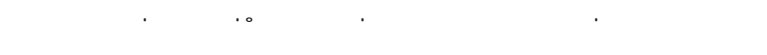

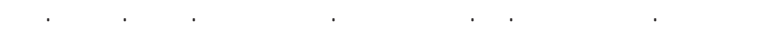

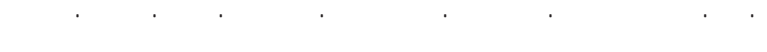

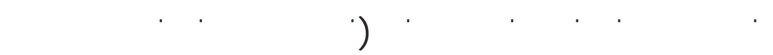

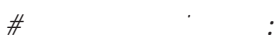

CĞ

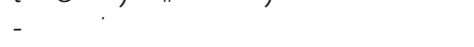

Article History:

Received: 11 February 2017

Accepted: 4 March 2017 
se întâlnește la același bolnav hipertensiune arterială supină și hipotensiune arterială ortostatică, coexistenţa acestora ridicând probleme terapeutice, întrucât tratamentul uneia poate agrava simptomele celeilalte. Pe de o parte, hipertensiunea arterială poate conduce la apariţia hipotensiunii ortostatice, iar pe de altă parte medicaţia antihipertensivă poate induce hipotensiune ortostatică sau o poate agrava, dacă aceasta este pre-existentă. Pacienţii cu hipertensiune arterială primară pot dezvolta hipotensiune ortostatică din cauza desensibilizării baroreceptorilor arteriali, ca urmare a creșterii persistente a tensiunii arteriale $(3,4)$. Frecvenţa hipotensiunii ortostatice la bolnavii hipertensivi crește paralel cu vârsta și cu nivelul tensiunii arteriale sistolice $(5,6)$. La pacienţii mai tineri, cauzele hipotensiunii ortostatice sunt de cele mai multe ori diferite: depleţia volemică (în urma vărsăturilor, sindroamelor diareice, hemoragice, tratamentului intempestiv cu diuretice) sau insuficienţa cronică autonomă.

\section{ETIOLOGIA HIPOTENSIUNII ORTOSTATICE}

Cele două mecanisme principale ale hipotensiunii ortostatice (insuficienţa autonomă și depleţia volemică) sunt întâlnite în cadrul mai multor patologii. Într-un studiu pe 100 de pacienţi internaţi consecutiv cu hipotensiune posturală s-a găsit următoarea distribuţie a etiologiei hipotensiunii: $27 \%$ insuficienţă autonomă primară, 35\% insuficienţă autonomă secundară (neuropatie diabetică sau insuficienţă autonomă paraneoplazică), $38 \%$ fără disfuncţie autonomă generalizată, tratamentul cu antidepresive fiind o cauză frecvent ignorată (7).

Hipotensiunea ortostatică poate fi primară sau secundară, acută sau cronică. Hipotensiunea ortostatică primară este întâlnită în boala Parkinson, atrofia multisistemică (sindromul Shy-Drager), insuficienţa autonomă pură, demenţa cu corpi Lewy, unele boli rare ereditare sau poate fi idiopatică (8). Hipotensiunea secundară poate fi iatrogenă (indusă de anumite medicamente), sau datorată diabetului zaharat, bolilor cardiovasculare (stenoza aortică, blocuri atrio-ventriculare, insuficienţa cardiacă, boala de nod sinusal, hipertensiune primară, hipertensiune pulmonară), insuficienţei renale, bolilor autoimune, neuropatiei toxice etanolice, afecţiunilor endocrine, amiloidozei, mielomului multiplu, sindroamelor paraneoplazice, bolilor cerebrovasculare, sclerozei multiple etc.

\section{FIZIOPATOLOGIE}

Homeostazia tensiunii arteriale implică mecanisme compensatorii care acţionează pentru menţinerea tensiunii arteriale și prevenirea remodelării cardiovasculare. În reglarea tensiunii arteriale intervin sistemul cardiovascular, nervos, renal și endocrin. Sistemul nervos autonom (simpatic și parasimpatic) joacă un rol important în ajustarea tensiunii arteriale. Sistemul nervos simpatic are un rol determinant pentru nivelul tensiunii arteriale și distribuţia debitului cardiac. Sistemul nervos parasimpatic intervine în reglarea tensiunii arteriale mai ales prin efectele cronotrope și inotrope negative.

Ridicarea din clinostatism în ortostatism conduce la reducerea rapidă a întoarcerii venoase la nivelul cordului, din cauza stagnării a 500-1.000 $\mathrm{ml}$ de sânge în membrele inferioare și circulaţia splanhnică, ceea ce are drept consecinţă scăderea umplerii ventriculare, cu scăderea debitului cardiac și a tensiunii arteriale. Această scădere a tensiunii arteriale induce un răspuns compensator din partea sistemului nervos simpatic și parasimpatic (reflexul baroreceptor), cu creșterea rezistenţei vasculare periferice, a întoarcerii venoase și a debitului cardiac, limitând astfel scăderea tensiunii arteriale. Aceste mecanisme compensatorii sunt responsabile de menţinerea valorii tensiunii arteriale la ridicarea în ortostatism, în mod normal apărând doar o mică scădere a tensiunii arteriale sistolice (cu 5-10 mm $\mathrm{Hg}$ ), o creștere a tensiunii arteriale diastolice (cu 5-10 mm Hg) și a alurii ventriculare. Bolnavii cu hipotensiune arterială prezintă afectarea unuia sau mai multor mecanisme compensatorii, cu prăbușirea valorilor tensiunii arteriale la ridicarea în ortostatism.

În insuficienţa autonomă există o alterare a neurotransmiterii noradrenergice în care neuronii simpatici nu eliberează noradrenalină în mod corespunzător. Eliberarea insuficientă de noradrenalină conduce la afectarea vasoconstricţiei și reducerea volumului intravascular intratoracic, ambele contribuind la apariţia hipotensiunii ortostatice. Absenţa creșterii normale reflexe a frecvenţei cardiace în urma scăderii tensiunii arteriale la ridicarea în ortostatism este un indicator al existenţei insuficienţei autonome. $\mathrm{Cu}$ toate acestea, tahicardizarea nu poate exclude insuficienţa autonomă.

\section{MANIFESTĂRI CLINICE}

Manifestările clinice de hipotensiune ortostatică apar în urma schimbării bruște a poziţiei 
corpului, mai exact la trecerea din clinostatism în ortostatism, însă pot apărea și posprandial sau după menţinerea îndelungată a ortostatismului, fiind datorate hipoperfuziei cerebrale (9). Acestea constau în ameţeală, vertij, senzaţie de slăbiciune generalizată, instabilitate posturală, fatigabilitate, vedere înceţoșată. Unele studii au raportat durere la nivelul gâtului, în zona cervicală posterioară si a umerilor (10-12). Intensitatea simptomelor poate fi variată, de la ușoară la severă. Pacienţii cu simptome severe prezintă stare presincopală sau chiar sincopă la trecerea în ortostatism. Există și cazuri de hipotensiune ortostatică asimptomatică, însă mai rare.

\section{DIAGNOSTICUL HIPOTENSIUNII ORTOSTATICE}

Diagnosticul de hipotensiune ortostatică se stabilește în urma decelării scăderii tensiunii arteriale sistolice cu cel puţin 20 mm Hg și/sau a scăderii tensiunii arteriale diastolice cu cel puţin 10 mm Hg în primele 2-5 minute de la trecerea din clinostatism în ortostatism (13). Frecvenţa cardiacă crește în mod normal imediat după ridicarea în ortostatism. Absenţa creșterii acesteia în contextul scăderii tensiunii arteriale indică prezenţa insuficienţei autonome.

Anamneza bolnavului cu hipotensiune ortostatică trebuie să obţină date referitoare la tratamentul ambulator al acestuia, la prezenţa unor simptome ca vărsături, diaree, hidratare insuficientă, febră, consumul cronic de alcool, antecedente personale patologice ca diabet zaharat, boală malignă, insuficienţă cardiacă cronică, afecţiuni neurologice. La examenul obiectiv trebuie să se caute semne de parkinsonism, neuropatie periferică, ataxie sau alte semne de disautonomie (constipaţie, disfuncţie erectilă etc). Analizele uzuale de laborator indicate în caz de hipotensiune ortostatică sunt hemoleucograma, ureea și creatinina serică, glicemia, HbA1C, ionograma serică, electroforeza proteinelor serice. De asemenea, este obligatorie efectuarea consultului cardiologic și electrocardiogramei, ca și consultul neurologic. La pacienţii la care se suspectează o neuropatie periferică se recomandă electromiograma și studiul conducerii nervoase periferice. Testul mesei inclinate (tilt test) este, de asemenea, util (14). La aproximativ $1 / 3$ dintre pacienţii cu hipotensiune ortostatică nu se poate identifica etiologia acesteia, chiar în urma efectuării unor investigaţii paraclinice extensive (15).

\section{COMPLICAȚIILE HIPOTENSIUNII ORTOSTATICE}

O serie de studii populaţionale au găsit o mortalitate de cauză cardiovasculară și mortalitate totală crescute în rândul pacienţilor cu hipotensiune ortostatică (16-18). Pacienţii cu hipotensiune ortostatică simptomatică au un risc crescut de căderi, cu morbiditate asociată crescută prin traumatismele secundare. Calitatea vieţii acestor bolnavi este scăzută, fiind afectaţi de tulburări depresive, tulburări anxioase, de probleme psihosociale, ca și de restricţii privind practicarea anumitor meserii la risc $(19,20)$.

\section{TRATAMENTUL HIPOTENSIUNII ORTOSTATICE}

Măsurile generale de informare și educare a pacienţilor sunt esenţiale în managementul hipotensiunii ortostatice. Pacientul trebuie să cunoască și să înţeleagă mecanismul apariţiei hipotensiunii ortostatice, ca și factorii declanșatori și agravanţi, cu scopul de prevenire a acestora. De asemenea, pacientul trebuie să recunoască semnele clinice „de alertă“ induse de modificările hemodinamice, pentru a putea aplica în timp util măsuri rapide de contracarare a acestora. Printre măsurile fizicale de prevenţie și tratament se numără ciorapii elastici compresivi, precum și compresia abdominală. Compresia membrelor inferioare și a abdomenului ameliorează toleranţa ortostatică la până la $40 \%$ din pacienţii simptomatici (21). Principalul inconvenient al acestei metode constă în dificultatea aplicării și purtării ciorapilor compresivi, mai ales de către pacienţii vârstnici și în special în timpul anotimpului călduros.

Tratamentul farmacologic se impune la bolnavii cu forme severe de hipotensiune ortostatică, intens simptomatici. Agenţii farmacologici utilizaţi sunt droxidopa, midodrine, piridostigmina, fludrocortizon și desmopresin, cu rezultate variabile. În prezent, droxidropa și midodrine sunt preferate, administrându-se în timpul zilei pentru a evita hipertensiunea nocturnă supină. Droxidropa ameliorează toleranța ortostatică la pacienţii cu hipotensiune ortostatică neurogenă (22). Tratamentul se iniţiază cu doze mici, care se cresc progresiv până la ameliorarea sau dispariţia simptomelor. Midodrin-ul are o eficienţă moderată în tratamentul hipotensiunii ortostatice, fără efecte secundare semnificative (23); se iniţiază tratamentul cu doza minimă si se up-titrează progesiv în funcţie de răspunsul la tratament. Fludrocortizonul se poate adăuga în schema de tratament, pentru expansiune volemică, administrarea sa fiind contraindicată în insuficienţa cardiacă, insuficienţa renală sau hipertensiunea arterială (24). 


\section{CONCLUZII}

Hipotensiunea arterială ortostatică este o afecţiune relativ frecventă în rândul populaţiei generale, în special al populaţiei vârstnice, fiind predictor de mortalitate și morbiditate semnificative.
Etiologia sa este reprezentată în majoritatea cazurilor de insuficienţa autonomă primară sau secundară. Tratamentul medicamentos al hipotensiunii ortostatice este de cele mai multe ori nesatisfăcător, impunându-se asocierea cu mijloace nefarmacologice.

Conflict of interest: none declared

Financial support: none declared

\section{BIBLIOGRAFIE}

1. Rutan G.H., Hermanson B., Bild D.E. et al. Orthostatic hypotension in older adults: the Cardiovascular Health Study. Hypertension 1992; 19:508-19.

2. Kaufmann H. Consensus statement on the definition of orthostatic hypotension, pure autonomic failure and multiple system atrophy. Clin Auton Res 1996;6:125-6.

3. Masuo K., Mikami H., Ogihara T. et al. Changes in frequency of orthostatic hypotension in elderly hypertensive patients under medications. Am J Hypertens 1996; 9:263-8.

4. Lagi A., Rossi A., Cornelli A. et al. Postural hypotension in hypertensive patients. Blood Pressure 2003; 12:340-4.

5. Applegate W.B., Davis B.R., Black H.R. et al. Prevalence of postural hypotension at baseline in the systolic hypertension in the elderly program (SHEP) cohort. J Am Geriatr Soc 1991;39:1057-64.

6. Strogatz D.S., Keenan N.L., Barnett E.M. et al. Correlates of postural hypotension in a community sample of elderly blacks and whites. J Am Geriatr Soc 1991; 39:562-6.

7. Robertson D., Robertson R.M. Causes of chronic orthostatic hypotension. Arch Intern Med 1994; 154:1620.

8. Carmen Adella Sirbu,

Emilia Furdu-Lungut, Cristina Florentina Plesa, Cristina Manuela Dragoi. Pharmacological treatment of relapsing remitting multiple sclerosis-where are we? Farmacia, 2016,Vol 64 (5), 651-655.
9. Metzler M., Duerr S., Granata R. et al. Neurogenic orthostatic hypotension: pathophysiology, evaluation, and management. J Neurol 2013; 260:2212.

10. Khurana R.K. Coat-hanger ache in orthostatic hypotension. Cephalalgia 2012; 32:731.

11. Robertson D., Kincaid D.W., Haile V., Robertson R.M. The head and neck discomfort of autonomic failure: an unrecognized aetiology of headache. Clin Auton Res 1994; 4:99.

12. Bleasdale-Barr K.M., Mathias C.J. Neck and other muscle pains in autonomic failure: their association with orthostatic hypotension. J R Soc Med 1998; 91:355.

13. Freeman R., Wieling W., Axelrod F.B. et al. Consensus statement on the definition of orthostatic hypotension, neurally mediated syncope and the postural tachycardia syndrome. Clin Auton Res $2011 ; 21: 69$

14. Gibbons C.H., Freeman R. Delayed orthostatic hypotension: a frequent cause of orthostatic intolerance. Neurology 2006; 67:28.

15. Sathyapalan T., Aye M.M., Atkin S.L. Postural hypotension. BMJ 2011; 342:d3128.

16. Fedorowski A., Melander O. Syndromes of orthostatic intolerance: a hidden danger. J Intern Med 2013; 273:322.

17. Luukinen H., Koski K., Laippala P., Airaksinen K.E. Orthostatic hypotension and the risk of myocardial infarction in the home-dwelling elderly. J Intern Med 2004; 255:486.

18. Fedorowski A., Stavenow L., Hedblad B. et al. Orthostatic hypotension predicts all-cause mortality and coronary events in middle-aged individuals (The Malmo Preventive Project). Eur Heart J 2010; 31:85.

19. Pezzoli M., Garzaro M., Pecorari G. et al. Orthostatic hypotension and psychiatric comorbidities in patients with dizziness. Am J Otolaryngol 2012; 33:432.

20. Perlmuter L.C., Sarda G., Casavant V. et al. A review of orthostatic blood pressure regulation and its association with mood and cognition. Clin Auton Res 2012; 22:99.

21. Podoleanu C., Maggi R., Brignole M. et al. Lower limb and abdominal compression bandages prevent progressive orthostatic hypotension in elderly persons: a randomized single-blind controlled study. J Am Coll Cardiol 2006;48:1425-32.

22. Keating G.M. Droxidopa: a review of its use in symptomatic neurogenic orthostatic hypotension. Drugs 2015;75:197-206.

23. Izcovich A., González Malla C., Manzotti M. et al. Midodrine for orthostatic hypotension and recurrent reflex syncope: a systematic review. Neurology 2014; 83:1170-7.

24. Maule S., Papotti G., Naso D. et al. Ortho-static hypotension: evaluation and treatment. Cardiovasc Hematol Disord Drug Targets 2007; 7:63-70. 